\title{
Lightening Effect of Skin Lightening Cream Containing Piper betle L. Extract in Human Volunteers
}

\author{
Sharifah Shakirah Syed Omar ${ }^{1,2} \oplus^{\infty}$, Hazrina Hadi ${ }^{1,2, *}$, Nadzira Mohd Hanif ${ }^{1}$, Hawa Mas Azmar Ahmad ${ }^{1}$ \\ and Shiow-Fern $\mathrm{Ng}^{3}$ \\ 1 Department of Pharmaceutical Technology, Faculty of Pharmacy, International Islamic University Malaysia, \\ Kuantan 25200, Pahang, Malaysia; shakirahsaggaf@gmail.com (S.S.S.O.); nadzirahanif@gmail.com (N.M.H.); \\ hawa.maa41@gmail.com (H.M.A.A.) \\ 2 Dermatopharmaceutics Research Group, International Islamic University Malaysia, \\ Kuantan 25200, Pahang, Malaysia \\ 3 Department of Pharmaceutical Technology, Faculty of Pharmacy, The National University of Malaysia, \\ Bangi 43600, Selangor, Malaysia; nsfern@ukm.edu.my \\ * Correspondence: hazrina@iium.edu.my; Tel.: +60-9-570-4853
}

check for updates

Citation: Omar, S.S.S.; Hadi, H.; Mohd Hanif, N.; Ahmad, H.M.A.; Ng, S.-F. Lightening Effect of Skin Lightening Cream Containing Piper betle L. Extract in Human Volunteers. Cosmetics 2021, 8, 32. https:// doi.org/10.3390/cosmetics8020032

Academic Editor: Francisco Solano

Received: 5 March 2021

Accepted: 21 April 2021

Published: 26 April 2021

Publisher's Note: MDPI stays neutral with regard to jurisdictional claims in published maps and institutional affiliations.

Copyright: (c) 2021 by the authors. Licensee MDPI, Basel, Switzerland. This article is an open access article distributed under the terms and conditions of the Creative Commons Attribution (CC BY) license (https:// creativecommons.org/licenses/by/ $4.0 /)$.

\begin{abstract}
Hyperpigmentation affects people globally with negative psychological impacts. Piper betle L. leaf (PBL) extract has many benefits including skin lightening which may reduce hyperpigmentation. The objective of this study was to develop an effective skin-lightening cream containing PBL with ideal characteristics. A formulation of base cream and PBL cream was prepared and characterized by centrifugation, particle size and zeta potential analysis, rheological profile studies and physical properties' observation. In vivo studies on 30 human subjects tested the effects of base and PBL cream on skin-lightening, hydration, trans-epidermal water loss (TEWL) and elasticity through weekly tests 4 weeks in duration. Base and PBL creams had a non-Newtonian property with acceptable color, odor, texture, zeta potential, particle size and showed no phase separation. The in vivo study indicated a significant reduction in melanin content and an improvement in skin tone for PBL cream but not in base cream. TEWL and elasticity also showed significant reduction for both formulations, indicating a healthier skin barrier and supple skin with consistent use, although hydration fluctuated with no significant changes. The developed PBL cream showed significant results in the reduction in melanin content and improving skin tone, which shows the formulation can confer skin-lightening effect.
\end{abstract}

Keywords: hyperpigmentation; Piper betle leaves; topical formulation; natural product

\section{Introduction}

Hyperpigmentation is a skin disorder that causes the skin to darken in small patches of certain area or it may cover a large area of the body. This skin disorder is caused by the excessive production of melanin by melanocytes of the skin epidermis [1]. It can also be caused by active melanocytes proliferating, thus increasing the number of melanocytes. This overproduction can be caused by an overabundance of sun exposure, hormonal changes in pregnancy, certain medications as well as endocrine diseases [1,2]. Solar lentigines, melasma, freckles, post-inflammatory hyperpigmentation and any other dark mark on the skin are examples of hyperpigmentation, as shown in Figure 1 [3]. Pigmentation on the skin is becoming a major aesthetic concern to many people. A study on the impact of pigmentary disorder on quality of life found that nearly half of the population studied felt self-conscious, unattractive and that other people were focusing on their skin, thus they put effort into hiding skin hyperpigmentation [4]. 


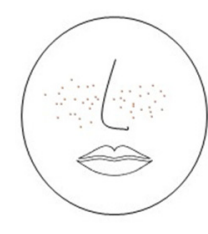

Freckles

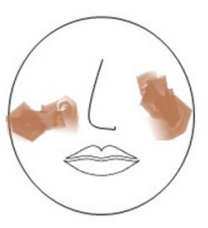

Melasma

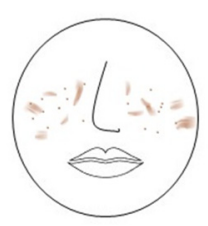

Solar lentigines

Figure 1. Illustration of some common hyperpigmentation issues.

Some of the treatment modalities for hyperpigmentation include topical skin lightening agents, chemical peeling, laser therapies and also surgery [1]. Based on guidelines, the use of topical skin-lightening agents acts as a first line therapy to tackle this matter [2]. The most common skin lightening agents are chemical based such as hydroquinone, arbutin, tretinoin and alpha hydroxyl-acids (kojic acid, gycolic acid and lactic acid). All of these agents act by inhibiting the activity of the tyrosinase enzyme, which in succession leads to the reduced production of melanin, hence the depigmenting or whitening effect [1]. However, these agents may cause adverse effects including skin irritation, contact dermatitis, ochronosis, permanent depigmentation and increasing the skin's UV sensitivity [2]. These discoveries sparked interest in finding alternative skin-lightening agents from natural sources such as plant extracts, with the belief that they are safer to use compared with synthetic chemical agents [5].

The leaf of Piper betle $\mathrm{L}$. has been reported to have many therapeutic benefits including a skin-lightening effect [6]. Piper betle L. is a plant native to peninsular Malaysia from the Piperaceae family which is easily obtained from local markets by the name "sireh" [7]. The skin lightening effect is believed to be contributed by a compound named hydroxychavicol (1-allyl-3,4-dihydroxybenzene). Researchers have found that its skin lightening effect is conferred through its anti-tyrosinase activity in the melanin synthesis pathway [8]. The pathway is depicted in Figure 2. In this study an oil in water cream containing Piper betle L. extract was formulated. The formulation was characterized to ensure that its properties are stable and suitable for consumer use. The efficacy of the fabricated formulation was evaluated on human volunteers to probe its effects on the skin barrier and functions.

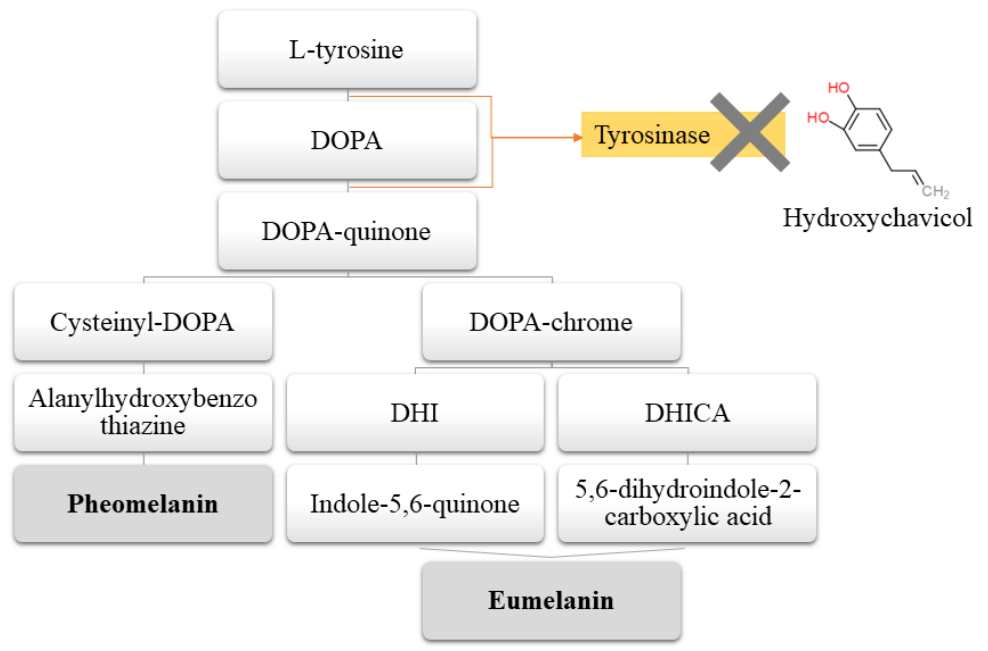

Figure 2. Activity of hydroxychavicol as anti-tyrosinase in the melanogenesis pathway.

\section{Materials and Methods}

The formulation consists of aqueous phase, oil phase and cold phase as detailed in Table 1, Section 2.3. Aqueous phase composed of water, lecithin (Tianjin Hexiyuan Technology Co Ltd., Tianjin, China), glycerin (IOI Acidchem Sdn Bhd, Perai, Pulau Pinang, Malaysia), chitosan acetate which the chitosan is from Sigma-Aldrich (St. Louis, USA) and the acetic acid from Merck (Darmstadt, Germany), disodium edetate ( $\mathrm{Xi}^{\prime}$ an lyphar Biotech 
Co., Ltd., Shaanxi, Xi'an, China) and the Piper betle L. leaf (PBL) extract. The PBL extract was extracted through subcritical water extraction using an accelerated solvent extractor (ASE) as specified in Section 2.1.

Table 1. Composition of Formulation.

\begin{tabular}{|c|c|c|}
\hline Composition & Function & $(\%) w / w$ \\
\hline \multicolumn{3}{|c|}{ Part A } \\
\hline Distilled water & Water phase & 64.40 \\
\hline Glycerin & Humectant & 5.00 \\
\hline Lecithin & Emulsifier & 5.00 \\
\hline Chitosan acetate & Permeation enhancer & 0.40 \\
\hline Piper betle L. extract & Active ingredient & 0.20 \\
\hline Disodium EDTA & Chelating agent & 0.20 \\
\hline \multicolumn{3}{|c|}{ Part B } \\
\hline Refined coconut oil & Emollients & 4.00 \\
\hline Olive oil & Emollients & 4.00 \\
\hline Squalane & Emollients & 3.00 \\
\hline Beeswax & Emulsifier & 4.00 \\
\hline Cocamidopropyl betaine & Surfactant & 5.00 \\
\hline Xanthan Gum & Thickener & 0.80 \\
\hline \multicolumn{3}{|c|}{ Part C } \\
\hline Euxyl ${ }^{\circledR}$ PE 9010 & Preservative & 0.40 \\
\hline Chamomile essential oil & Fragrance & 0.50 \\
\hline Ascorbic Acid & Antioxidant & 0.10 \\
\hline Tocopherol acetate & Antioxidant & 2.00 \\
\hline Pectin & Emulsifier & 1.00 \\
\hline \multicolumn{2}{|c|}{ Total } & $100 \%$ \\
\hline
\end{tabular}

The oil phase comprises of beeswax (Kahlwax, Trittau, Germany), xanthan gum (Deosen Biochemical Ltd., Picataway, NJ, USA), refined coconut oil and olive oil from Natures Natural India (New delhi, India), cocamidopropyl betaine (Haihang Industry Co., Ltd., Jinan, China) and squalane from Kono Chem Co., Ltd. (Xi'an, China). Finally, the cold phase includes ascorbic acid from Xi'an lyphar Biotech Co., Ltd., tocopherol acetate from Natures natural India, pectin from Kono Chem Co., Ltd. (Xi'an, China), Euxyl-PE (IMCD Malaysia Sdn. Bhd, Petaling Jaya, Malaysia) and chamomile essential oil (Hunan Nutramax Inc., Yongzhou, China).

The chemicals used for HPLC analysis were acetonitrile and glacial acetic acid (Merck, Darmstadt, Germany). Deionized water was obtained from Nex Power 4000 Ultra-Reversed Osmosis Water Purification System equipment (Human Corp., Songpa-gu, Korea). The reference standard of hydroxychavicol with $99.9 \%$ purity was purchased from Chromadex (Irvine, CA, USA). For in vivo studies, elasticity pads for the elasticity probe were obtained from Naman Technology Sdn. Bhd (Petaling Jaya, Malaysia). For microbial study, tryptic soy broth, tryptic soy agar, cetrimide agar, sabouraud $4 \%$ dextrose agar and mannitol salt phenol-red agar were purchased from Merck (Darmstadt, Germany).

\subsection{Piper betle L. Extraction}

The leaves were freshly dried at $50^{\circ} \mathrm{C}$ for $24 \mathrm{~h}$ then ground into powder. Subcritical water extraction of PBL was performed by using Dionex ${ }^{\mathrm{TM}} \mathrm{ASE}^{\mathrm{TM}} 350$ Accelerated Solvent Extractor (Dionex Corp., Sunnyvale, CA, USA) at a constant pressure of 1500 psi with distilled water as extraction solvent. Obtained sample extract was kept at $-80{ }^{\circ} \mathrm{C}$ and freeze dried prior to the High-Performance Liquid Chromatography (HPLC) analysis. Chromatographic separation was performed by using a LiChrospher ${ }^{\circledR}$ column $(250 \times 4.0$ $\mathrm{mm}$ i.d.) with a $5 \mu \mathrm{m}$ pore size (Merck, Darmstadt, Germany). Mobile phase consisted of $2 \%$ acetic acid diluted in deionized water $(v / v)$ : acetonitrile $(75: 25, v / v)$ in an isocratic elution 
mode. The solvent flow rate was maintained at $1.0 \mathrm{~mL} / \mathrm{min}$ at a column temperature of 30 ${ }^{\circ} \mathrm{C}$ with samples being detected at $280 \mathrm{~nm}$.

\subsection{Antioxidant and Anti-Tyrosinase Assay}

The antioxidant assay was performed in a 96-well plate in minimal light exposure. All samples were dissolved in methanol at a concentration of $1.0 \mathrm{mg} / \mathrm{mL}$. The assay was performed by comparing pure hydroxychavicol, hydroxychavicol rich fraction and crude PBL extract to ascorbic acid as a reference standard. Samples were later mixed with $100 \mu \mathrm{L}$ $\mathrm{DPPH}$ solution. The plate was incubated in the dark at room temperature for $30 \mathrm{~min}$. The absorbance of the solutions was then measured with a microplate reader (Tecan Infinite M200 Nanoquant; Grodi, Austria) at $517 \mathrm{~nm}$.

The anti-tyrosinase assay was performed using dopachrome method in minimal light exposure with some modifications [9]. Preparation of tyrosinase mushroom enzyme solution and L-DOPA solution were adapted from Sigma protocol (EC1.14.18.1). Samples were dissolved in dimethyl sulphoxide (DMSO) at a concentration of $1.0 \mathrm{mg} / \mathrm{mL}$. Kojic acid was used as a reference standard for samples of pure hydroxychavicol, hydroxychavicol rich fraction and crude extract. The assay was carried out using a 96-well plate and the absorbance was measured using a microplate reader at $475 \mathrm{~nm}$. Each well consisted of $40 \mu \mathrm{L}$ of sample dissolved in DMSO, $80 \mu \mathrm{L}$ of phosphate buffer (pH 6.8), $40 \mu \mathrm{L}$ of tyrosinase enzyme $(1000 \mathrm{U} / \mathrm{mL})$ and $40 \mu \mathrm{L}$ of L-DOPA. The final volume in each well was $200 \mu \mathrm{L}$.

\subsection{Oil-in-Water Cream Formulation}

Cream development started by placing the ingredients as listed in Table 1 into two different beakers comprising of aqueous and oil phase, which were both heated up to $75^{\circ} \mathrm{C}$ in a water bath for $20 \mathrm{~min}$. Both mixtures were mixed thoroughly using a glass rod. The water phase was then added to the oil phase and homogenized with a homogenizer at a speed of $3500 \mathrm{rpm}$ for $20 \mathrm{~min}$. The cream formed was left to cool to room temperature before adding the cold phase ingredients. The complete mixture was homogenized once again for another $20 \mathrm{~min}$.

\subsection{Characterization}

\subsubsection{Physical Analysis}

The organoleptic properties as well as the physical appearance of the formulated cream were analyzed for acceptability to potential users. The properties include appearance, color, odor and texture of the formulation [10].

\subsubsection{Forced Centrifugation}

We placed $10 \mathrm{~g}$ of the cream formulation in a centrifugal tube and centrifuged at $5000 \mathrm{rpm}$ for $10 \mathrm{~min}$ at $25^{\circ} \mathrm{C}$. Centrifugation study was employed to study the resistance of cream towards being centrifuged [11].

\subsection{3. $\mathrm{pH}$}

$\mathrm{pH}$ of the formulation was measured using a calibrated $\mathrm{pH}$ meter (Metler Toledo, Greifensee, Switzerland). The $\mathrm{pH}$ of the formulation was determined by diluting $1 \mathrm{~g}$ of the formulation in $9 \mathrm{~mL}$ of distilled water to form a concentration of $10 \%(w / w)$.

\subsubsection{Particle Size Analysis}

Particle size was analyzed using a laser particle size analyzer (BT-9300 H, Dandong Baite Instrument Co., Ltd., Dandong, China). Cream was diluted to approximately 1:1000 in the sample cell containing distilled water to prevent multiple scattering effect before running the machine. We diluted $0.1 \mathrm{~mL}$ of the cream with $100 \mathrm{~mL}$ of distilled water. Samples were run in triplicate at $25^{\circ} \mathrm{C}$ to obtain an average result. 


\subsubsection{Zeta Potential Determination}

The zeta potential was measured using Zetasizer (ZEN 1600, Malvern, UK). Samples were diluted with deionized water to 1:100 to avoid multiple scattering effects. We diluted $0.1 \mathrm{~mL}$ of cream with $10 \mathrm{~mL}$ of deionized water. The sample was then placed in the capillary cell for measurement in triplicates. All measurements were carried out at temperature of $25^{\circ} \mathrm{C}$.

\subsubsection{Rheological Analysis}

The rheological parameter was measured using stress-controlled rheometer (HAAKE MARS, Thermo Scientific, Bremen, Germany). A cone and plate with diameter of $35 \mathrm{~mm}$ and a gap of $1 \mathrm{~mm}$ was used. Sample was loaded on to the lower plate of the rheometer while the cone and plate equilibrate to $25^{\circ} \mathrm{C}$. A shear rate ramp with shear rates of $0.1 \mathrm{~s}^{-1}$ $100 \mathrm{~s}^{-1}$ was applied to the sample.

\subsubsection{Microbial Limit Count}

Sample was subcultured in laminar air flow chamber on Mannitol Salt Agar and on Cetrimide Agar to determine presence of Staphylococcus aureus and Pseudomonas aeruginosa, respectively. Total Aerobic Microbial Count (TAMC) and Total Yeast and Mold Count (TYMC) was also done on Tryptic soy agar and Sabouraud dextrose agar, respectively. We diluted $1 \mathrm{~g}$ of the sample was diluted to a 1 in 10 dilution using phosphate buffer solution $\mathrm{pH}$ 7.2. We used $10 \mathrm{~mL}$ of the sample for inoculation on the tryptic soy broth and then incubated at $30-35^{\circ} \mathrm{C}$ for $18-24 \mathrm{~h}$. The sample was then sub cultured on a mannitol salt agar plate and incubated for $18-72 \mathrm{~h}$ at $30-35^{\circ} \mathrm{C}$. The same steps were repeated but subcultured on cetrimide agar and incubated for $18-72 \mathrm{~h}$ at $30-35^{\circ} \mathrm{C}$. For the determination of Total Aerobic Microbial Count (TAMC) and Total Yeast and Mold Count (TYMC) a dilution of 1:10 of the cream in phosphate buffer solution $\mathrm{pH} 7.2$ was prepared. Pour-plate method was conducted where $1 \mathrm{~mL}$ of the diluted sample was added in a Petri dish and 15-20 mL of tryptic soy agar for TAMC was added. Plate was then incubated at $30-35^{\circ} \mathrm{C}$ for 5 days or less. Similar steps were repeated on Sabouraud dextrose agar for TYMC. The plate for TYMC was then incubated at $20-25^{\circ} \mathrm{C}$ for 5 days or less.

\subsection{In Vivo Study}

A skin condition assessment was performed using DermaLab ${ }^{\circledR}$ Combo at International Islamic University Malaysia (IIUM), Kuantan, Pahang. The study was registered and approved by National Medical Research Register (NMRR) and IIUM Research Ethics Committee (IREC) with identification number 36,572 and IREC870, respectively. The number of participants was 30 people who were divided into two groups of 13 and 17. Informed consent forms were given and collected from each participant. The study conducted was a single-blinded study where the participants did not know whether they received cream containing Piper betle L. extract or cream without the extract. The exclusion criteria included having any skin disease such as eczema, psoriasis or severe acne, had any skin disease in the past 3 months and was treated with medication, on any medications that may affect skin's response, damaged skin around test site, exposed to sun excessively, using other product at test site and not willing to stop, and not able to comply to the daily use of test cream. The inclusion criteria required participants with normal skin conditions.

A week before the baseline skin condition assessment was performed, participants were asked to stop using any products other than basic shower creams or soap at the test site. Baseline skin condition assessment was performed with DermaLab ${ }^{\circledR}$ Combo using the melanin content, hydration, trans-epidermal water loss (TEWL) and elasticity probes. Right after the baseline measurement, participants were given the cosmetic cream either containing the PBL extract or the placebo to be applied twice daily at the volar area of the left forearm. A bottle of cream was given to the participant for 4 weeks' study duration. Participants applied $5 \mathrm{mg} / \mathrm{cm}^{2}$ or $0.1 \mathrm{~mL}$ of cream to an area of $20 \mathrm{~cm}^{2}$. 
Using a $1 \mathrm{~mL}$ syringe, participants withdrew $0.1 \mathrm{~mL}$ to be applied on the designated study site. To ensure that the cream was being applied at the same area each time, as well as to make sure that the cream has applied to the tested area, a tool illustrated in Figure 3 was provided to the participants to aid the process. Using the tool, an exact area can be positioned for cream application and skin testing. The participants performed a weekly skin condition assessment for 4 weeks to evaluate the effects of the formulation. Analysis was performed to find significant difference in the parameters measured $(p<0.05)$ before and after application of the cream.

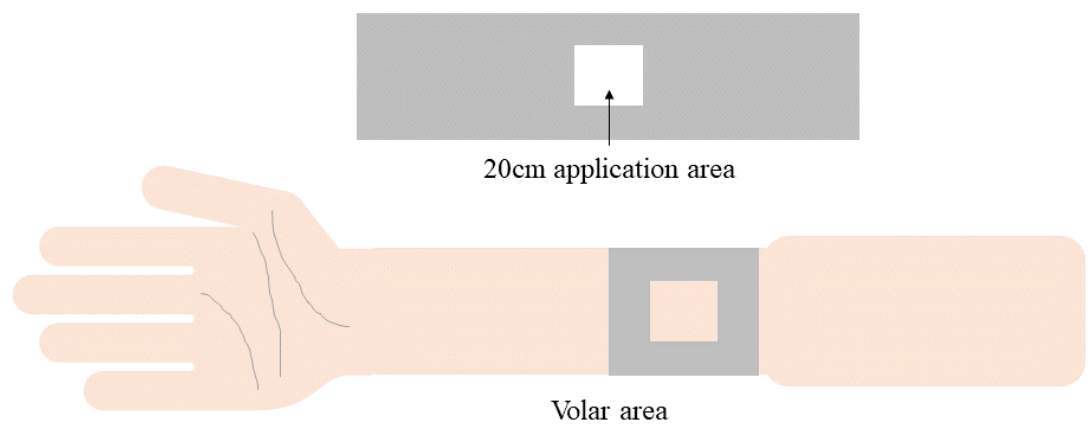

Figure 3. Cream application area and application tool.

\subsubsection{Dermalab ${ }^{\circledR}$ Combo}

The skin assessment was performed using DermaLab ${ }^{\circledR}$ Combo (Dermalab ${ }^{\circledR}$ Series Skinlab Combo), manufactured by Cortex Technology which was validated to be a reliable skin analysis equipment [12]. It consists of a main unit screen connected to several types of probe. Assessment of the skin condition was performed on the volar aspect of the left forearm specifically between the wrist and the elbow. The volar area of the forearm was wiped first with an alcohol swab and left to dry before performing the assessment. The assessment was performed by placing the probe on the studied area. This assessment took an estimated $10 \mathrm{~min}$ for each participant.

\subsubsection{Skin Color Probe}

The skin color probe is used to measure the melanin content of the skin and skin tone through illumination by high intensity white LEDs. The probe was calibrated before being placed at three different areas to get the average reading. Based on the melanin value, results were classified based on Dermalab ${ }^{\circledR}$ combo classification provided by Cortex technology into type I to type VI which are Celtic, Caucasian white, Mixed, Mediterranean, Asian and Black. Skin tone was measured using the same probe through Comisson Internationale de I'Ecalairage $(\mathrm{CIE}) \mathrm{L}^{*} \mathrm{a}^{*} \mathrm{~b}^{*}$ color code system where $\mathrm{L}^{*}$ reflects the lightness or darkness of the color, $\mathrm{a}^{*}$ indicates the amount of red or green, which best shows erythema, and $b^{*}$ indicates the amount of yellow or blue, which could measure pigmentation $[13,14]$. From this information the Individual Typology Angle $\left(\operatorname{ITA}^{\circ}\right)$, which represents the skin type, was calculated through this equation

$$
\operatorname{ITA}^{\circ}=\left[\text { Arc tangent }\left(\mathrm{L}^{*}-50\right) / \mathrm{b}^{*}\right] \times 180 / 3.14159
$$

Based on the angle calculated, the skin was classified into groups based on Fitzpatrick classification consisting of very light, light, intermediate, tan, brown, dark. The ITA is inversely proportional with melanin index, such that the higher the melanin index, the lower the $\operatorname{ITA}^{\circ}[15]$.

\subsubsection{Pin Hydration Probe}

The hydration probe was used to measure the hydration or moisture of the skin through the conducting properties of the upper layer of the skin when exposed to different voltage or known as conductance measurement [14]. The probe was calibrated to ensure 
accuracy of reading, then the pin hydration probe was pressed onto the volar forearm at four different places and the score was displayed on screen in the unit of $\mu$ Siemens $(\mu S)$.

\subsubsection{TEWL Open Chamber Probe}

The TEWL probe was used to measure water loss from the skin, which also reflects the condition of the skin barrier through its water retaining ability. There are two sides of the probe, namely the perforated foam (which faced up) and the open end (which is the side that was pressed lightly or moderately against the skin). A TEWL probe protector was placed at the open end to prevent cross-contamination and was replaced for each participant. The measurement of TEWL is presented in gram per square meter per hour $\left(\mathrm{g} / \mathrm{m}^{2} / \mathrm{h}\right)$. Normal skin results range between $2-10 \mathrm{~g} / \mathrm{m}^{2} / \mathrm{h}$.

\subsubsection{Elasticity Suction Probe}

The elasticity probe was used to measure the skin retraction time by applying suction on the skin surface through a vacuum chamber. A sticker pad is placed on the surface of the probe then placed on the volar forearm. The sticker pad helps maintain contact with the skin by sufficient suction, hence allowing reproducible results. The suction elevates the skin surface to $1.5 \mathrm{~mm}$, which then retracted to its normal state. The time it takes to retract from being elevated depends on the skin's elasticity or age group. The normal score for aged 20 and above is $300-550$. Aged 30 and above is $600-800$ and more than 800 for above 60 years old.

\subsection{Statistical Analysis}

SPSS version 21 was used for data analysis. All data obtained are expressed in mean $\pm \mathrm{SD}$ or mean $\pm \mathrm{SEM}$. Repeated measures ANOVA was used to analyze the mean and determine statistically significant difference shown by $p$ value $<0.05$.

\section{Results}

\subsection{Piper betle L. Extraction}

The optimum temperature for subcritical water extraction of hydroxychavicol is $100{ }^{\circ} \mathrm{C}$, which gave the highest percentage of hydroxychavicol content of $8.33 \pm 0.02 \%$, $w / w(p<0.05)$, while the optimum time is $60 \mathrm{~min}$ with the total extraction time of $180 \mathrm{~min}$, with percentage content of hydroxychavicol of $7.53 \pm 0.03 \%, w / w$. Over a 60 min extraction time interval with the total run time of $180 \mathrm{~min}$ and $10^{\circ} \mathrm{C}$ in temperature, the total extraction yield obtained was $40.56 \% w / w$ with a total hydroxychavicol yield of $30.58 \pm 0.12 \mathrm{mg} / \mathrm{g}$ Piper betle leaves.

\subsection{Antioxidant and Anti-Tyrosinase Activity}

Antioxidant activity was strongest in hydroxychavicol rich fraction $(3.70 \pm 2.74$ $\mu \mathrm{g} / \mathrm{mL})$ followed by pure hydroxychavicol $(6.52 \pm 1.93 \mu \mathrm{g} / \mathrm{mL})$ and crude betle leaf extract $(6.71 \pm 2.42 \mu \mathrm{g} / \mathrm{mL})$ reflected by lower IC50 value. The hydroxychavicol-rich fraction contained vital polyphenols that possesses antioxidant properties [16]. However, these values are lower than the standard ascorbic acid. Anti-tyrosinase activity reflected by IC50 was best in hydroxychavicol-rich fraction $(8.72 \pm 1.05 \mu \mathrm{g} / \mathrm{mL})$ followed by crude Piper betle leaf extract $(10.69 \pm 1.76 \mu \mathrm{g} / \mathrm{mL})$ and lastly pure hydroxychavicol $(16.70 \pm 4.53 \mu \mathrm{g} / \mathrm{mL})$. A study was conducted tyrosinase inhibition assay on essential oil, methanolic and aqueous extracts of $P$. betle and they observed the strongest inhibition of tyrosinase belonged to a fraction of $P$. betle leaf extract and was related to the content of hydroxychavicol and eugenol in the samples [17]. There were no significant difference between each sample for both antioxidant and antityrosinase activity.

\subsection{Characterization}

The cream prepared was assessed in terms of appearance. There was slight difference in the color of the formulation where the base formulation was white in color while the 
PBL cream had a more yellowish hue. This difference in color is caused by the dark brown color of the extract influencing the color of the end product. Texturewise, both formulations appear smooth with a slight shine. As both formulations had chamomile essential oil, the odor of both creams was pleasant. A centrifugation study performed to assess the stability of the formulation, specifically the occurrence of phase separation, showed no instability of the formulations. The $\mathrm{pH}$ of the PBL cream and the base cream were both acidic at $4.67 \pm 0.20$ and $4.80 \pm 0.12$, respectively. For the microbial limit study, no growth was observed in TAMC, TYMC, Staphylococcous aureus and Pseudomonas aeruginosa tests.

Both formulations have small particle size in which for base cream $0.986 \pm 0.005 \mu \mathrm{m}$ is considered ultrafine $(0.1-1 \mu \mathrm{m})$ while PBL cream $1.086 \pm 0.029 \mu \mathrm{m}$ shows a fine particle size $(1-10 \mu \mathrm{m})$ [18]. The spans obtained were $1.423 \pm 0.032$ and $1.763 \pm 0.081$ for base cream and PBL cream, respectively indicating that both formulations obtained a span value of less than 2 . The results show both formulations having low zeta potentials of $-58.03 \pm 0.55 \mathrm{mV}$ and $-61.20 \pm 1.25 \mathrm{mV}$ for base and PBL cream, respectively. Both formulations follow a non-Newtonian flow, portraying nonlinear relation between shear stress and shear rate. Both formulations portray a pseudoplastic flow at which the increase in shear stress will increase the shear rate and reduce viscosity [19]. From the graph in Figure 4, a hysteresis loop with a blue line can be seen, which reflects thixotropy, while the red lines show decreasing viscosity as a result of increasing shear rate. The base cream and PBL cream obtained low apparent viscosity at shear rate of $100 \mathrm{~s}^{-1}$ with values of $1.043 \pm 0.0005$ Pa.s and $1.206 \pm 0.0020$ Pa.s.
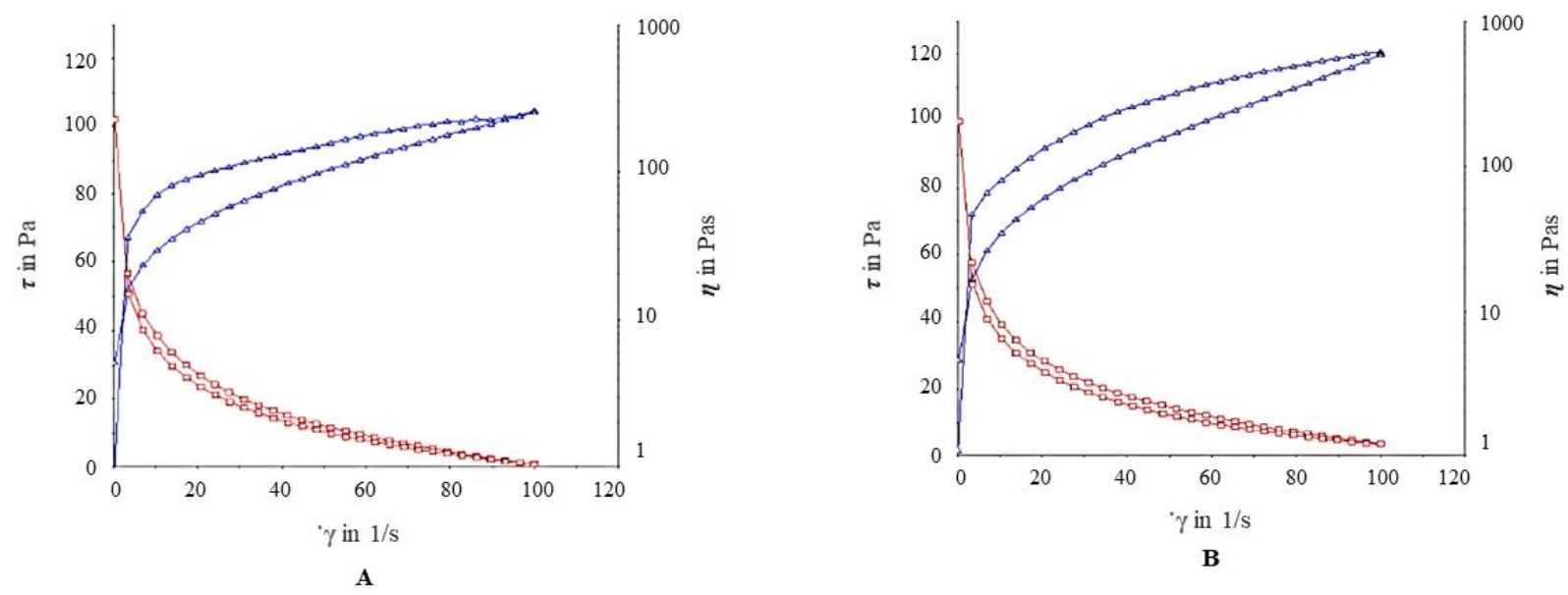

Figure 4. Rheological Analysis Graph. Blue Line Shows Relationship of Shear Stress (T) and Shear Rate (y), While Red Line Shows Relationship of Viscosity ( $\mathrm{y}$ ) and Shear Rate (y). (Abbreviations; (A) is Base Cream and (B) is PBL Cream).

\subsection{In Vivo Study}

Melanin content for PBL cream showed an overall significant reduction $(p=0.000)$ while base cream did not show significant reduction $(p=0.0596)$ across the 4 week study, as shown in Figure 5. The PBL cream reduced the melanin content from $\sum=37.14$ at week 0 to $\sum=33.48$ at week 4 . A pairwise comparison shows that reduction in melanin content by PBL cream in week 3 and 4 were both significant compared to week $1(p=0.034)$ $(p=0.024)$ and week $2(p=0.008)(p=0.006)$. The base cream, on the other hand, remained stagnant with slight fluctuations of melanin content throughout the 4 weeks, starting with $\Sigma=36.1$ at baseline and $\Sigma=36.02$ at the final reading. Both melanin content for PBL cream and base cream maintained within the Mixed type (III) and Mediterranean type (IV) with melanin index 20-50 and 30-60, respectively. For skin tone, the PBL cream group showed a significant reduction $(p=0.003)$ throughout the 4 week study duration (Figure 6$)$. To be more specific, the reduction in week 3 and week 4 were significant compared to week 2 . Week 0 showed a value -40.06 , which is categorized as dark $\left(<-30^{\circ}\right)$ and later reduced to -31.8 in week 4 , which is almost entering the brown skin classification $\left[\left(-30^{\circ}\right)-10^{\circ}\right]$. 
The changes in skin tone for the base cream group were not significant. The values from baseline to week 4 fluctuated between -36.38 to -39.59 yet remained within the dark skin classification.

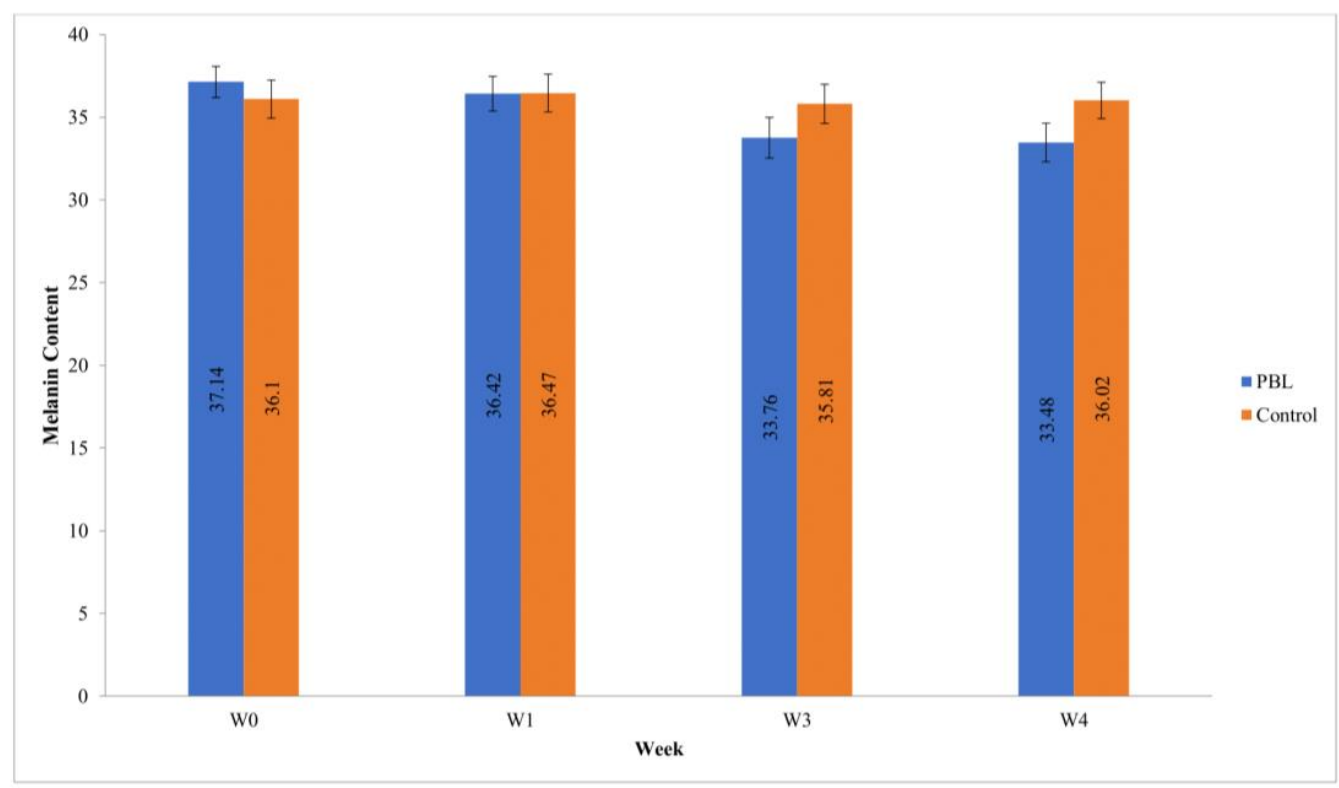

Figure 5. Melanin Content for PBL Cream Group (Mean $\pm \mathrm{SEM}, n=17$ ) and for Control Group (Mean \pm SEM, $n=13$ ).

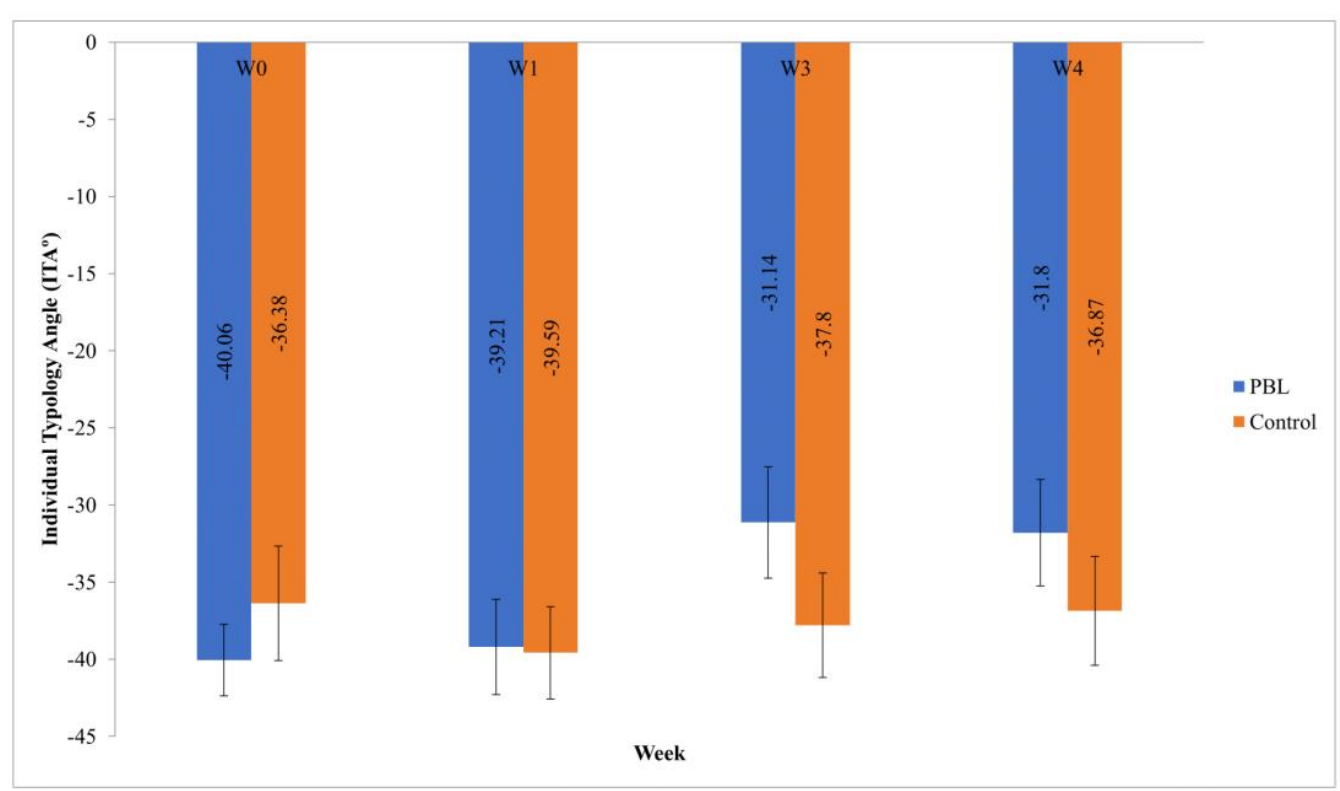

Figure 6. Skin tone for PBL Cream Group (Mean \pm SEM, $n=17$ ) and for Control Group (Mean \pm SEM, $n=13$ ).

The overall results for hydration over 4 weeks in Figure 7 showed no significant results for PBL cream and base cream with values of $p=0.814$ and $p=0.179$, respectively. Both formulations showed fluctuations from baseline to week 4 . TEWL showed significant results for PBL cream ( $p=0.021)$ and base cream $(p=0.012)$ throughout the 4 week study, as shown in Figure 8. The PBL cream showed a reduction from a baseline of $\sum=7.71$ to $\sum=3.50$ at the end of week 4 , while the base cream also showed the same pattern where the values reduced from a baseline of $\sum=7.75$ to $\sum=3.62$ in week 4 . Both creams started showing significant improvement from week 1 . The results obtained for both formulations were well within the normal range of $2-10 \mathrm{~g} / \mathrm{m}^{2} / \mathrm{h}$. Both PBL cream and base cream also 
showed significant results in terms of elasticity, with values $p=0.000$ for both formulations. The results are depicted in Figure 9. The skin elasticity improved as the retraction time reduced from $\sum=556.76$ at baseline to $\sum=448.76$ at week 4 for the PBL cream. The base cream, on the other hand, reduced from baseline $\sum=554.77$ to $\sum=410.31$ at week 4. Although there were fluctuations throughout the study period, the values were all lower than the baseline value, indicating that the cream formulation did have a role in improving the skin's elasticity. The initial baseline values for both groups were a little over the 30-50 years old age category, which ranges from 550 to $800 \mathrm{~ms}$. The reduction in the retraction time over the following weeks indicated the skin becoming more elastic, remaining within the age range of 20-30-year-old ranging from 300 to 550 (similar to the participants' age range).

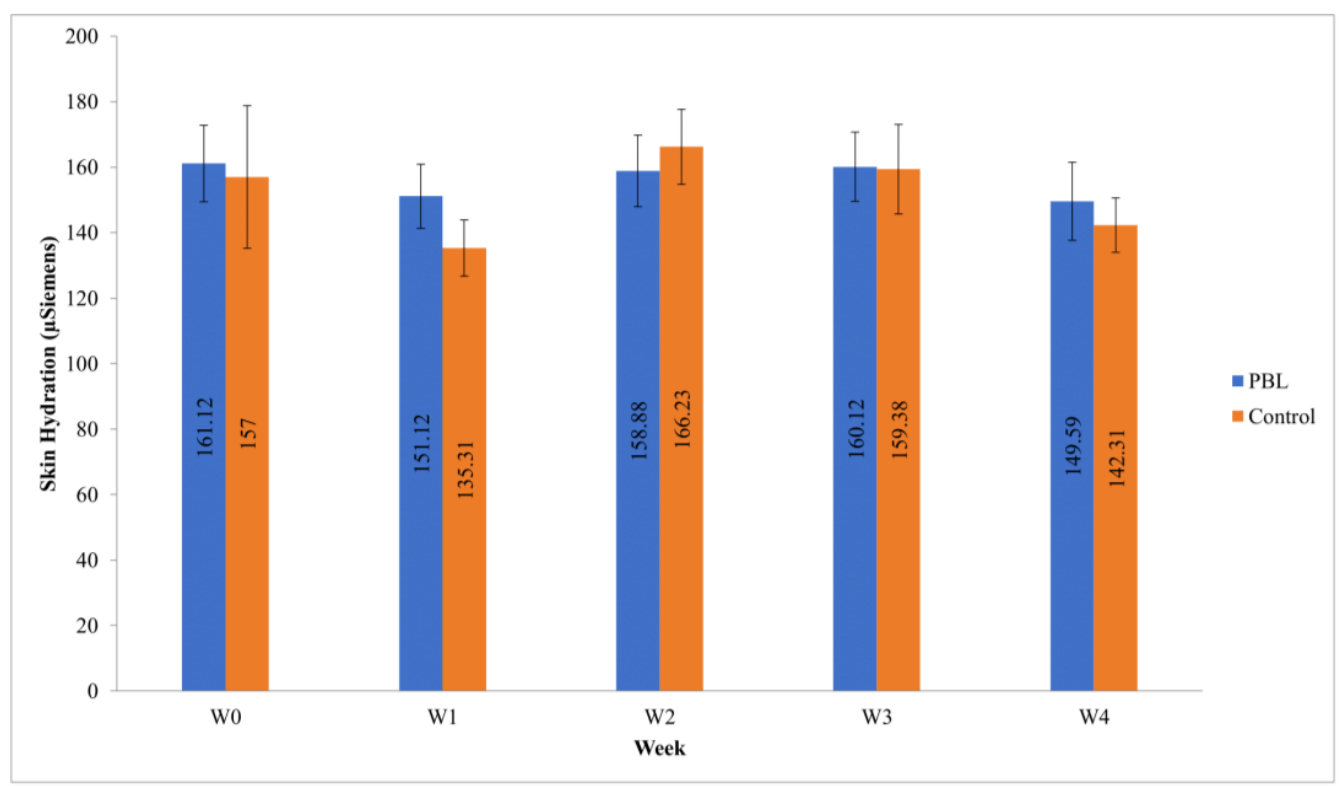

Figure 7. Hydration for PBL Cream Group (Mean $\pm \mathrm{SEM}, n=17$ ) and for Control Group (Mean \pm SEM, $n=13$ ).

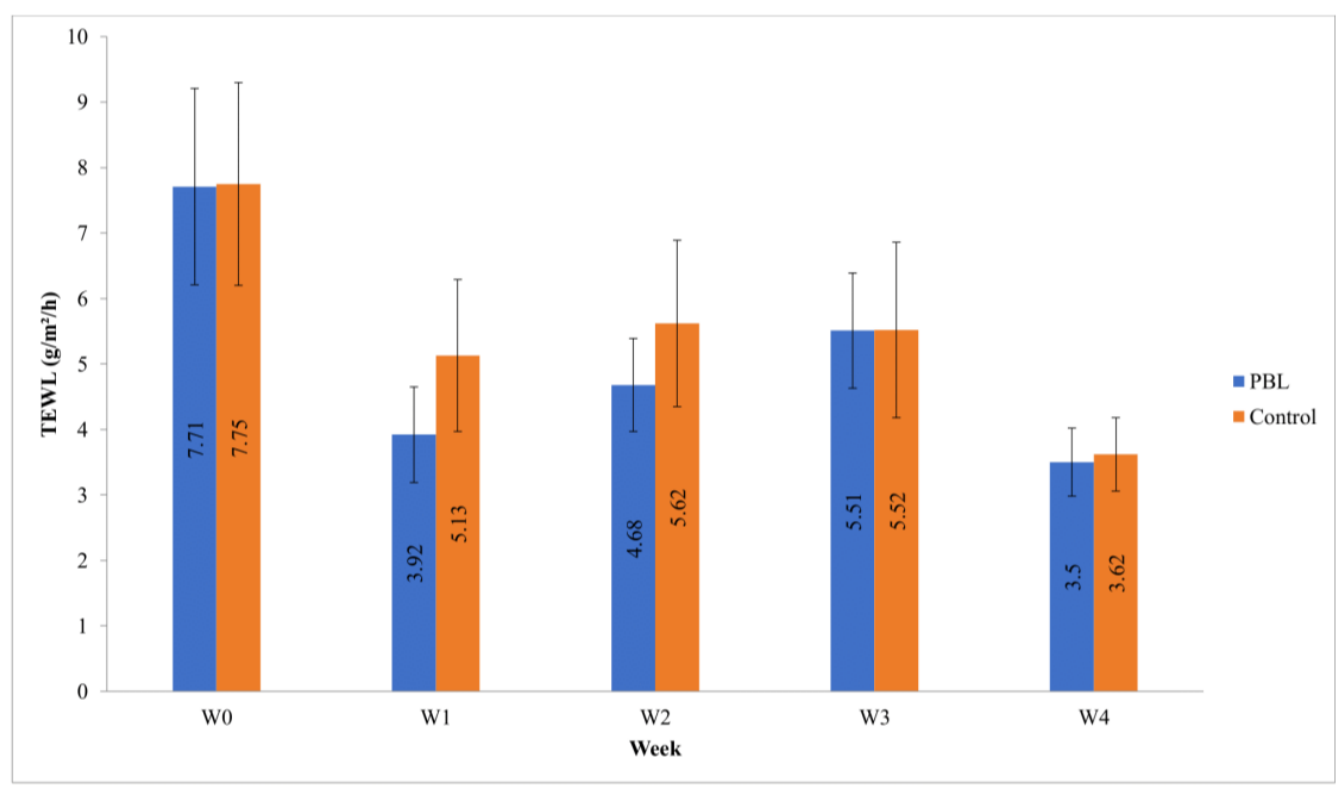

Figure 8. TEWL for PBL Cream Group (Mean \pm SEM, $n=14$ ) and for Control Group (Mean \pm SEM, $n=13$ ). 


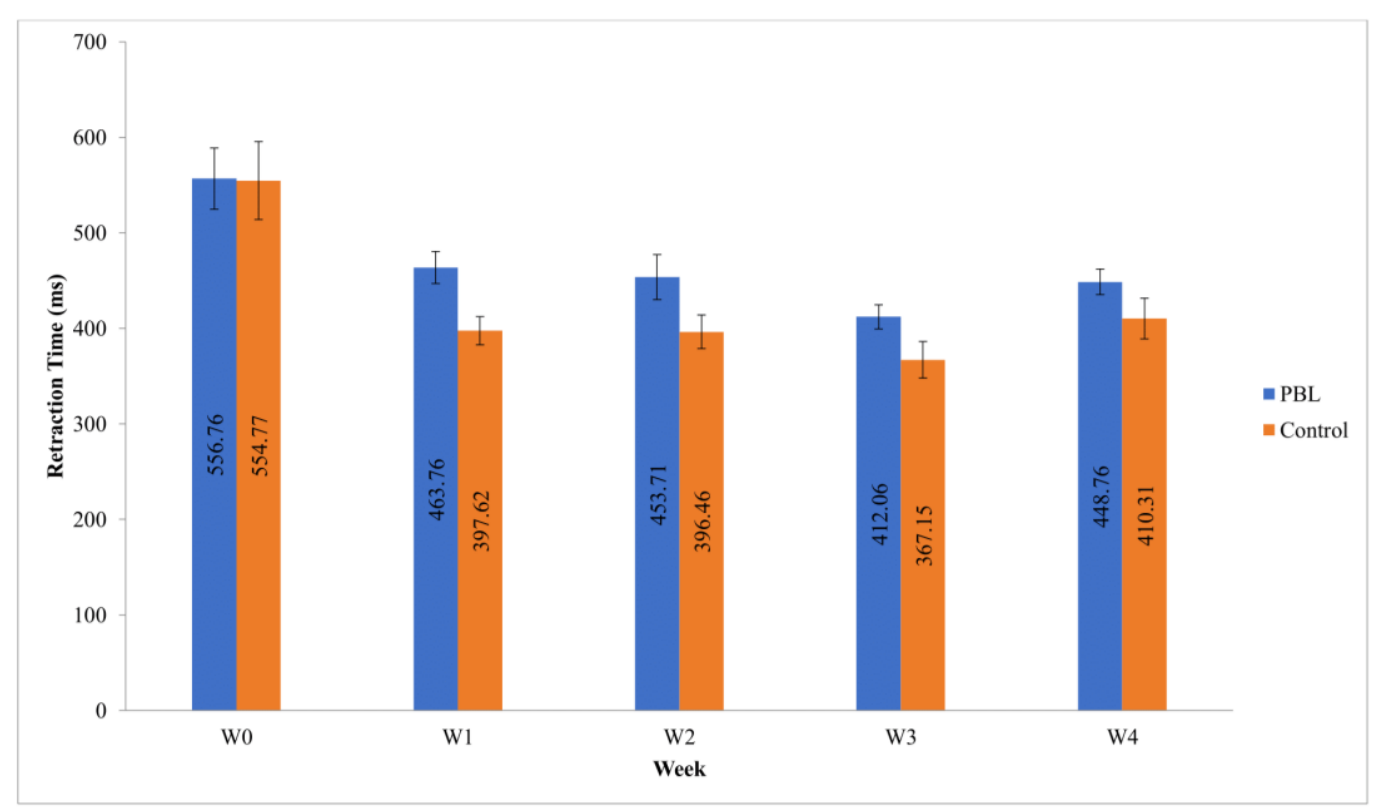

Figure 9. Elasticity for PBL Cream Group (Mean $\pm \mathrm{SEM}, n=17$ ) and for Control Group (Mean \pm Scheme 13).

\section{Discussion}

\subsection{Characterization}

Both formulations exhibited no creaming, foaming, coalescence or phase separation. The presence of lecithin, pectin, xanthan gum and beeswax as emulsifying agents stabilized the cream, preventing it from separating into its oil and aqueous components [20]. Both formulations have an acidic $\mathrm{pH}$ that is suitable to be applied on human skin with potentially no irritation. Most formulations have a $\mathrm{pH}$ between 3 and 8 [21]. To return the skin specifically the acid mantle to its normal condition of an average $\mathrm{pH}$ of 5.5 , an acidic formulation is preferred for topical application [22]. For the microbial limit study, no growth was observed for all tests, most likely due to the presence of the preservative, which is a combination of phenoxyethanol and ethylhexylglycerin [23]. The PBL cream also has an advantage due to the antimicrobial action of the PBL extract [7]. Both formulations have small particle size, which favors better viscosity and hence enhanced stability [24]. Both formulations obtained a span value of less than 2, indicating near monodispersed formulation, which also enhances stability [25]. The values of the zeta potential for both formulations are lower than $-30 \mathrm{mV}$ indicating that the formulations are stable as the particles or droplets repel each other [26]. This reduces the chances of the particle coalescing or flocculating and thus destabilizing. The flow behavior of the formulation was characterized through rheology studies, which helped in ensuring the viscosity and flow behavior was suitable for its purpose for skin application. The apparent viscosity of both formulations reduces with increasing shear rates, which represents an ease of application and spread for users. Ease of application has been associated with shear rates of up to $120 \mathrm{~s}^{-1}$ [27].

\subsection{In Vivo Study}

The relationship between melanin content and the individual typology angle (ITA) is inversely related, where an increase in melanin will result in a decrease in the ITA. The PBL cream showed a consistent decrease in melanin where in turn an increase in ITA can be seen. This positive result seen in the PBL cream in comparison to base cream may be contributed by a bioactive compound in Piper betle L., hydroxychavicol, which has a skin lightening effect exerted by its anti-tyrosinase activity $[5,8]$. This compound inhibits the tyrosinase enzyme, hence reducing the production of melanin and providing a skin-lightening effect. The results also prove that, although there are other ingredients 
with skin lightening potential in the formulation, such as ascorbic acid, tocopherol acetate and chitosan, their content is not significant enough to cause any skin lightening effect, as shown by the base cream results.

The hydration results showed no specific increasing or decreasing pattern for both formulations. To obtain consistency in hydration data is difficult as there are many external factors other than cream application that may affect the skin's hydration. One of the many factors includes water intake, which can cause very dehydrated skin results when not taken sufficiently [28]. Other than that, environmental factors, such as exposure to the sun, may also lead to skin dehydration, as skin is one of the main routes for water loss through sweating [29]. Other variables that can influence the skin's hydration are the weather on the day of the test (relative humidity) and skin exposure to water (shower, washing hands) which may cause inconsistency in the hydration data collected [30]. These reasons may influence the participant's skin's condition, hence explaining the fluctuating data throughout the study period.

As TEWL reflects the condition of the skin barrier, it shows that the skin barriers of all participants remained healthy and normal throughout study. Furthermore, the consistent application of the cream, regardless of whether participants were using base cream or PBL cream, showed the TEWL values reducing from the initial baseline. This indicates improvement in the skin barrier, specifically the state and function of the stratum corneum in preventing water loss from the skin [31]. The formulation consisted of lipids, humectants, occlusive and emollients, which helped in improving the skin barrier. Emollients and occlusive protect the barrier whilst locking in moisture, while humectants attract more water to the stratum corneum. The occlusives and emollients found in this formulation are olive oil, coconut oil, squalane and beeswax; and the humectants include glycerin and lecithin. Although there were slight fluctuations, this is a given as there are many environmental and individual factors that may affect the TEWL readings, such as air flow, relative humidity, air temperature, sweating, hair and skin temperature [32].

Similar to TEWL, the improvement of skin's elasticity was significant from the first week after baseline assessment. The possible mechanism in the improvement of skin's elasticity is the antioxidant activity of PBL from its phenols and flavonoids, which contribute to the free radical scavenging activity. Eugenol, a phytochemical in PBL, was found to have highest antioxidant activity in comparison to P. fragile, P. umbellatum, P. aduncum, and P. pellucidum extracts [33]. Hydroxychavicol and several other ingredients of the formulation, such as ascorbic acid and tocopherol acetate, also have antioxidant activity [34,35]. These compounds can scavenge for reactive oxygen species (ROS) and slow down the aging process precipitated by the reduction in skin elasticity. The improvement in TEWL values, which indicate improvement in skin barrier, may also play a role as it reflects healthy skin, which includes having good elasticity [36].

\section{Conclusions}

In conclusion, a stable skin-lightening cream containing PBL was able to be formulated. The characteristics of the cream, including its organoleptic properties, $\mathrm{pH}$, particle size, zeta potential, rheological profile and microbial limit were all desirable and suitable for consumer use. The in vivo studies showed a reduction in melanin content and improvement of skin tone, proving the efficacy of the extract against the tyrosinase enzyme. The formulation itself has been proven to give benefits beyond skin lightening, which include improvement in skin barrier as reflected by significant improvement of TEWL value. The antioxidant properties of the extract and ingredients of the formulation proved to be beneficial as well through the improvement in the skin's elasticity. The formulation could potentially be a new alternative in the skin lightening arena. 
Author Contributions: Conceptualization, H.H.; methodology, H.H., S.S.S.O., N.M.H., and H.M.A.A.; analysis, S.S.S.O., N.M.H., and H.M.A.A.; investigation, S.S.S.O., N.M.H., and H.M.A.A.; resources, H.H., S.-F.N.; data curation, H.H., S.-F.N.; writing-original draft preparation, H.H., S.-F.N., S.S.S.O., N.M.H., and H.M.A.A.; writing - review and editing, S.S.S.O., and H.H.; visualization, H.H., S.-F.N.; supervision, H.H., S.-F.N.; project administration, H.H.; funding acquisition, H.H. All authors have read and agreed to the published version of the manuscript.

Funding: This research was funded by The Ministry of Higher Education Malaysia, grant number PRGS15-009-0019.

Institutional Review Board Statement: The study was conducted according to the guidelines of the Declaration of Helsinki, and approved by the Institutional Review Board (or Ethics Committee) of the International Islamic University Malaysia Research Ethics Committee (IREC870, 21 April 2017) and the National Medical Research Register under the authority of the Institute of Clinical Research, Ministry of Health Malaysia (36572, October 2017).

Informed Consent Statement: Informed consent was obtained from all subjects involved in the study.

Acknowledgments: The authors acknowledge the International Islamic University Malaysia (IIUM) for administrative and technical support throughout the research investigation.

Conflicts of Interest: The authors declare no conflict of interest. The funders had no role in the design of the study; in the collection, analyses, or interpretation of data; in the writing of the manuscript, or in the decision to publish the results.

\section{References}

1. Khoo, Y.T.; Halim, A.S. Treatment modalities for hyperpigmented skin lesions: A brief overview. J. Surg. Dermatol. 2016, 1, 71-79. [CrossRef]

2. Desai, S.R. Hyperpigmentation Therapy: A Review. J. Clin. Aesthetic Dermatol. 2014, 7, $13-17$.

3. Gillbro, J.M.; Olsson, M.J. The melanogenesis and mechanisms of skin-lightening agents-existing and new approaches. Int. J. Cosmet. Sci. 2011, 33, 210-221. [CrossRef] [PubMed]

4. Beresniak, A.; Auray, J.-P.; Duru, G.; Aractingi, S.; Krueger, G.G.; Talarico, S.; Adam, A.-S.; Piot, B.; Dupont, D.; De Linares, Y. Impact of pigmentary disorders on quality of life in Japan: Interest of the BeautyQoL instrument. J. Cosmet. Laser Ther. 2015, 17, 313-317. [CrossRef] [PubMed]

5. Jennifer, C.; Stephie, C.M.; Abhishri, S.B.; Shalini, B.U. A Review on Skin Whitening Property of Plant Extracts. Int. J. Pharma Bio Sci. 2012, 3, 332-347.

6. Aumeeruddy-Elalfi, Z.; Gurib-Fakim, A.; Mahomoodally, M. Kinetic studies of tyrosinase inhibitory activity of 19 essential oils extracted from endemic and exotic medicinal plants. S. Afr. J. Bot. 2016, 103, 89-94. [CrossRef]

7. Foo, L.W.; Salleh, E.; Mamat, S.N.H. Extraction and Qualitative Analysis of Piper Betle Leaves for Antimicrobial Activities. Int. J. Eng. Technol. Sci. Res. 2015, 2, 2394-3386.

8. Majeed, M.; Bani, S.; Pandey, A.; Anand-tathapudi, S. A Composition and a Method of Treating CNS Disorders and HyPerpigmentation. US Patent US12/900,727, 12 April 2012.

9. Salleh, W.M.N.H.W.; Ahmad, F.; Khong, H.Y. Antioxidant and Anti-tyrosinase Activities from Piper officinarum C.DC (Piperaceae). J. Appl. Pharm. Sci. 2014, 4, 87. [CrossRef]

10. Smaoui, S. Cosmetic emulsion from virgin olive oil: Formulation and bio-physical evaluation. Afr. J. Biotechnol. 2012, 11, 9664-9671. [CrossRef]

11. Smaoui, S.; Ben Hlima, H.; Ben Chobba, I.; Kadri, A. Development and stability studies of sunscreen cream formulations containing three photo-protective filters. Arab. J. Chem. 2017, 10, S1216-S1222. [CrossRef]

12. Hadi, H.; Awadh, A.I.; Hanif, N.M.; Suhaimi, M.S.M.; Sidik, N.F.A.M.; Rani, M.R.N.M. The investigation of the skin biophysical measurements focusing on daily activities, skin care habits, and gender differences. Ski. Res. Technol. 2015, 22, 247-254. [CrossRef] [PubMed]

13. Seo, Y.K.; Kim, S.J.; Boo, Y.C.; Baek, J.H.; Lee, S.H.; Koh, J.S. Effects of p-coumaric acid on erythema and pigmentation of human skin exposed to ultraviolet radiation. Clin. Exp. Dermatol. 2010, 36, 260-266. [CrossRef] [PubMed]

14. Cortex Technology DermaLab®Series. SkinLab Combo Instruction Manual; Cortex Technology: Hadsund, Denmark, $2012 ;$ pp. 7-38.

15. Wilkes, M.; Wright, C.; Du Plessis, J.L.; Reeder, A. Fitzpatrick Skin Type, Individual Typology Angle, and Melanin Index in an African Population. JAMA Dermatol. 2015, 151, 902-903. [CrossRef] [PubMed]

16. Masaki, H. Role of antioxidants in the skin: Anti-aging effects. J. Dermatol. Sci. 2010, 58, 85-90. [CrossRef] [PubMed]

17. Row, L.-C.M.; Ho, J.-C. The Antimicrobial Activity, Mosquito Larvicidal Activity, Antioxidant Property and Tyrosinase Inhibition of Piper Betle. J. Chin. Chem. Soc. 2009, 56, 653-658. [CrossRef]

18. Merkus, H.G. Particle Size Measurements: Fundamentals, Practice, Quality; Springer: Berlin/Heidelberg, Germany, 2009 ; Volume 17. 
19. Rodrigues, F.; Sarmento, B.; Amaral, M.H.; Oliveira, M.B.P.P. Exploring the antioxidant potentiality of two food by-products into a topical cream: Stability, In Vitro and In Vivo evaluation. Drug Dev. Ind. Pharm. 2015, 42, 880-889. [CrossRef]

20. Krstonošić, V.; Dokić, L.; Nikolić, I.; Milanović, M. Influence of xanthan gum on oil-in-water emulsion characteristics stabilized by OSA starch. Food Hydrocoll. 2015, 45, 9-17. [CrossRef]

21. Loden, M. The clinical benefit of moisturizers. J. Eur. Acad. Dermatol. Venereol. 2005, 19, 672-688. [CrossRef]

22. Khan, B.A.; Akhtar, N.; Khan, H.; Braga, V.D.A. Development, characterization and antioxidant activity of polysorbate based $\mathrm{O} / \mathrm{W}$ emulsion containing polyphenols derived from Hippophae rhamnoides and Cassia fistula. Braz. J. Pharm. Sci. 2013, 49, 763-773. [CrossRef]

23. Lores, M.; Llompart, M.; Alvarez-Rivera, G.; Guerra, E.; Vila, M.; Celeiro, M.; Lamas, J.P.; Garcia-Jares, C. Positive lists of cosmetic ingredients: Analytical methodology for regulatory and safety controls-A review. Anal. Chim. Acta 2016, 915, 1-26. [CrossRef]

24. Khor, Y.P.; Koh, S.P.; Long, K.; Long, S.; Ahmad, S.Z.S.; Tan, C.P. A Comparative Study of the Physicochemical Properties of a Virgin Coconut Oil Emulsion and Commercial Food Supplement Emulsions. Molecules 2014, 19, 9187-9202. [CrossRef]

25. Santos, J.L.; Gaspar, F. Production of Near Monodisperse Particles Using Milling and Membrane Separation. US Patent US9,937,470B2, 10 April 2018.

26. Coulman, S.A.; Anstey, A.; Gateley, C.; Morrissey, A.; McLoughlin, P.; Allender, C.; Birchall, J.C. Microneedle mediated delivery of nanoparticles into human skin. Int. J. Pharm. 2009, 366, 190-200. [CrossRef]

27. Adeyeye, M.C.; Jain, A.C.; Ghorab, M.K.M.; Reilly, W.J. Viscoelastic evaluation of topical creams containing microcrystalline cellulose/sodium carboxymethyl cellulose as stabilizer. AAPS PharmSciTech 2002, 3, 16-25. [CrossRef]

28. Jéquier, E.; Constant, F. Water as an essential nutrient: The physiological basis of hydration. Eur. J. Clin. Nutr. 2009, 64, 115-123. [CrossRef]

29. Choi, J.; Ghaffari, R.; Baker, L.B.; Rogers, J.A. Skin-interfaced systems for sweat collection and analytics. Sci. Adv. 2018, 4, eaar3921. [CrossRef] [PubMed]

30. Egawa, M.; Tagami, H. Comparison of the depth profiles of water and water-binding substances in the stratum corneum determined in vivo by Raman spectroscopy between the cheek and volar forearm skin: Effects of age, seasonal changes and artificial forced hydration. Br. J. Dermatol. 2007, 158, 251-260. [CrossRef]

31. Kottner, J.; Lichterfeld, A.; Blume-Peytavi, U. Transepidermal water loss in young and aged healthy humans: A systematic review and meta-analysis. Arch. Dermatol. Res. 2013, 305, 315-323. [CrossRef] [PubMed]

32. Ferguson, J.; Yeshanehe, W.; Matts, P.; Davey, G.; Mortimer, P.; Fuller, C. Assessment of skin barrier function in podoconiosis: Measurement of stratum corneum hydration and transepidermal water loss. Br. J. Dermatol. 2013, 168, 550-554. [CrossRef] [PubMed]

33. Widowati, W.; Wijaya, L.; Wargasetia, T.L.; Bachtiar, I.; Yelliantty, Y.; Laksmitawati, D.R. Antioxidant, anticancer, and apoptosisinducing effects of Piper extracts in HeLa cells. J. Exp. Integr. Med. 2013, 3, 225-230. [CrossRef]

34. Peng, C.; Wang, X.; Chen, J.; Jiao, R.; Wang, L.; Li, Y.M.; Zuo, Y.; Liu, Y.; Lei, L.; Ma, K.Y.; et al. Biology of Ageing and Role of Dietary Antioxidants. BioMed Res. Int. 2014, 2014, 831841. [CrossRef] [PubMed]

35. Sharma, S.; Khan, I.A.; Ali, I.; Ali, F.; Kumar, M.; Kumar, A.; Johri, R.K.; Abdullah, S.T.; Bani, S.; Pandey, A.; et al. Evaluation of the Antimicrobial, Antioxidant, and Anti-Inflammatory Activities of Hydroxychavicol for Its Potential Use as an Oral Care Agent. Antimicrob. Agents Chemother. 2008, 53, 216-222. [CrossRef] [PubMed]

36. Del Rosso, J.; Zeichner, J.; Alexis, A.; Cohen, D.; Berson, D. Understanding the Epidermal Barrier in Healthy and Com-promised Skin: Clinically Relevant Information for the Dermatology Practitioner: Proceedings of an Expert Panel Roundtable Meeting. J. Clin. Aesthet. Dermatol. 2016, 9, S2-S8. 